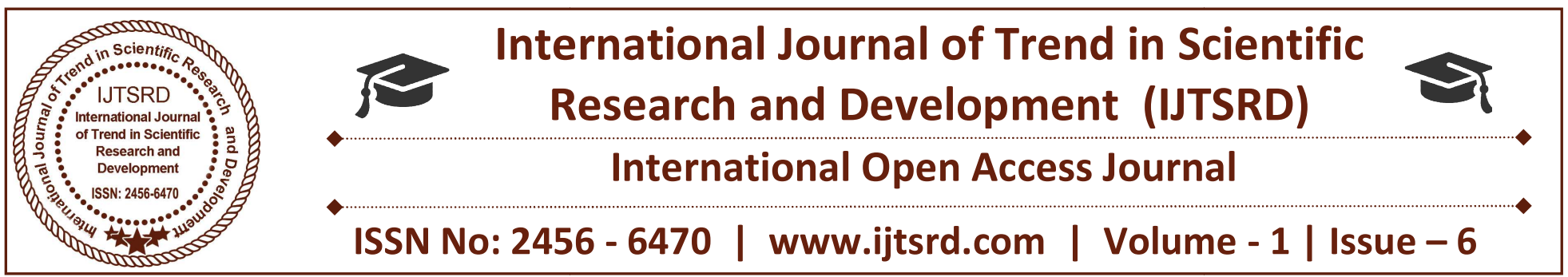

\title{
Roadmap of Six Sigma for Engineering Colleges
}

\author{
Mr. K. R. Gawande \\ Research Scholar, Shri J. J. T. University, \\ Jhunjhunu, Rajasthan, India
}

\author{
Prof. Dr. Rajeev V. V. \\ Principal, Sabar Institute of Technology \\ for Girls, Sabarkantha, Gujarat, India
}

\section{ABSTRACT}

A quality improvement tool called Six Sigma and its extension Lean Sigma has gained lot of attention and importance in service sector especially in engineering education. Six Sigma has several benefits in education and specifically provides a competitive edge over others. As per the old belief that only manufacturing organizations can be benefitted by Six Sigma, now a day study found the tremendous applications and applicability of Lean and Six Sigma in engineering colleges. There are still a number of issues related to the nature of education systems that must be resolved before the full benefits of Six Sigma can be realized. In this paper, the issue related with the practical application and implementation of Six Sigma through various angles as such: analytical, institutional, and personal point are studied. Awareness of the existence of such issues, if not the answers to all of them, is a pre-requisite to effective adoption of Six Sigma tools. A general roadmap for Six Sigma that can be applicable in engineering colleges is presented here.

Keywords: Zero defects, Lean and Six Sigma; DPMO; Service sector; Engineering education, Quality Management

\section{INTRODUCTION}

Since 1980 Six Sigma has found applications in manufacturing organisations and because of its tremendous benefits and effectiveness it has been accepted by many organisations. The tools of Six Sigma along with its statistical thinking have attracted many organisations as well. Design for Six Sigma or DFSS and Lean Six Sigma have gained much attention because of their effective outputs for built in performance at the stage of design and considerable efficiency at the stage of production.

As Six Sigma promises to reduce the rejection rate, which is termed as DPMO or defects per million opportunities, its principles are spread beyond manufacturing to service and up to education. There is a quite large use of Six Sigma and/or Lean Sigma in service sectors, which was earlier, thought the area of only manufacturing sector. We find now a days there is a boon of service sectors from off line firms to on line firms, providing various types of services and hence Six Sigma with its tools find a perfect place to capture the attention of these firms. This is the real time for Six Sigma to rise today and find its place in these service organizations particularly in engineering education. It is realized however as there are basic differences in manufacturing and service, a number of pragmatic issues came in to existence during its actual application, some of which may not even have been brought up to the attention of Six Sigma learners. It is certainly useful to discuss such issues and their impact on the effectiveness of Six Sigma; even when complete solutions are not available, the mere awareness would play an important role in defining one's understanding of the potential - and perhaps limitations as well - of the tools of Six Sigma, and helping to shape realistic expectations on outcomes of application projects anywhere.

In this paper the author focuses three general aspects, though these are not limited to, as (1) the analytical level; (2) the institutional level, and (3) the personal level. Such classification of items will help formulating counter-plans or solutions, although there 
could be other ways, for example presenting an allinclusive analysis in accordance to the DMAIC (DoMeasure-Analyse-Improve-Control) methodology and a general roadmap of Six Sigma for engineering colleges.

\section{SERVICE SECTOR AND ENGINEERING EDUCATION}

Service sector provides services only they do not create tangible products and this is the main common characteristic of all service sectors. Besides this they can take various shapes and forms like picking your clothes from your door step for laundry to taking lunch in a restaurant, or peace campaign in a war prone area, the list and experience of service is quite vast. Sometimes attempts are made to formally and positively define a service system though most Six Sigma practitioners tend to use a reverse approach, namely regarding anything non-manufacturing as service. Description or definition of service by exception may have difficulties, for example it would put certain types of human effort such as agriculture and warfare into ill-defined categories. However, if one is to limit one's attention to systems commonly encountered in modern and developed communities such as transportation, healthcare, finance, education - then the concept of service quality is easier to grasp. Hence for the sake of explaining the topic, here the definition of service is considered as said above and not as rigorous as been put forward by some experts.

As global competition in education becoming more intense, institutions are trying to implement strategies that allow them become more efficient, increase quality and productivity, and stay ahead of their competition. Over the years, there have been different programs or methodologies that institutions have adopted with the purpose of achieving enhanced operational performance and overall quality of the, let us say, engineering education. Six Sigma is one of the strategies that have gained more popularity during recent years, being adopted by some selected institutions in engineering education as well.

In spite of the challenges and difficulties of implementing Six Sigma in an academic environment, the literature shows that there are Six Sigma project successes in selected universities and institutions. Various authors have written articles about Six Sigma in education, role of academia in Six Sigma education, including case studies also.

\section{PROCESS OF BENCHMARKING AND THE ROADMAP}

The Six Sigma improvement model typically has five phases: Define, Measure, Analyse, Improve and Control: the same is casted to suit the engineering education setting. As shown in the figure 1 the college management is solely responsible for creating change environment in the college, which is the utmost requirement of any Six Sigma project. Management is the main driving force behind all activities that determines the success and failure of the Six Sigma project in the college.

Phase 1- Define: In the Define phase, the college has to form a Six Sigma team, including members from different departments and students as well, affected by the problem. The engineering college has to define the project charter mentioning clearly, responsibility and accountability. The team clearly specifies the problem and tries to quantify its qualitative impact on the overall engineering education and engineering college. The SIPOC diagram is resulted in the define phase. The team identifies metrics to assess the impact of the problem in the past, and to document improvements as the problem is fixed.

Phase 2- Measure: In the Measure phase, the Six Sigma team studies the academic and other process in engineering college and measurements associated with the problem. The team produces process maps and assesses the accuracy and precision of measurement systems. If necessary, the team establishes new metrics. The team identifies potential causes for the problem by applying a variety of statistical tools. The data for the potential causes of variation is collected and some major causes are differentiated termed as CTQ's.

Phase 3- Analyze: In the Analyze phase, the Six Sigma team determines what actually causes the problem. To do this, they apply a variety of statistical tools to test hypotheses and experiment on the process. Many times surveys, discussions and interviews are carried out to get insight in to the causes of the problems and their remedies. Once the relationship between the causes, effects and their remedies is understood, the team can determine how best to improve the process, and how much benefit to expect from the improvement.

Phase 4- Improve: In the Improve phase, the Six Sigma team implements changes to improve process performance. The remedies that came out in the analyse phase are implemented in improve phase, the 
improvement is again checked with some statistical tools and via some charts and graphs. The data is compared with the already stated objectives. Using the metrics already deployed, the team monitors the process to verify the expected improvement.

Phase 5- Control: In the Control phase, the Six Sigma team selects and implements methods to control future process variation. These methods could include documented procedures or statistical process control methods. This vital step assures that the same problem will not return in the future. With the process completed, the Six Sigma team disbands or if required it again takes the same or other problem to reduce process variation with higher/stringent objectives. Monitoring and comparing is the motto of this phase otherwise there lies the threat that the process may slip to its original state.

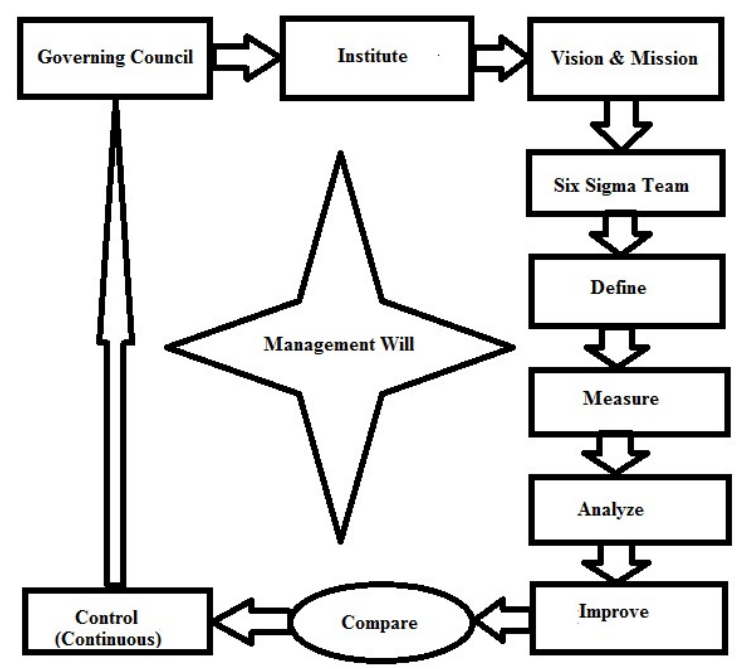

Fig. 1 Six Sigma Roadmap (general) in an Institute

\section{PRODUCT ISSUES}

In the study of quality management, customer satisfaction and business competitiveness of educational institutes there are a number of attributes of educational institutes that differentiate educational institutes from service and manufacturing. These may be categorized as follows:

\section{Identification of "defects" and, those are critical to quality:}

a. What constitutes a defect or defective could be very personal and hence subjective.

b. Delays are common in the recognition of defects or defectives.

c. A defect or defective is often more readily noticed (and seems more critical) than a "good" outcome. d. Level of quality tends to be measured and compared via a negative scale (e.g. DPMO (defects per million opportunities), instead of yield; complaints about educational system and facilities tend to be more attention-catching than compliments).

\section{Nature or basis for improvement:}

a. In a given study, the process in question can be, and often is, more relevant or felt more important than the product.

b. An instance of service tends to have to be highly customized for all the students (like standardization or mass production in manufacturing).

c. The role of raw material, that is input students and faculties, is usually high.

d. Inventorization, i.e. accumulation of services, is normally not done.

\section{Feasibility of applying analytical tools:}

a. Standardization, calibration and benchmarking could be inadequate, difficult, or sometimes impossible.

b. Product quality relates much more with information flow and utilization than what many traditional quality practitioners are used to.

c. Available information tends to be quantitative (i.e. continuous or measured data) rather than qualitative (i.e. discrete or attribute data).

d. Educational systems do not lend themselves readily to data-intensive methodologies such as those entailed in Six Sigma.

\section{Situation or institute specific issues:}

a. Specification limits or tolerances not only tend to be arbitrary or impossible, it could also be location/society-dependent and time-varying.

b. System boundary could be difficult to draw in a study; noise is usually large and, by definition, and nearly not controllable.

c. Customers themselves could be voluntarily or involuntarily involved in the way service is generated.

d. Cultural factors, values and ethics could be involved in judgments. Thus a person familiar with manufacturing process studies has to adopt a very different approach when it comes to educational systems. Most educational systems are in need of improvement in the sense of a Kano quality system -- Kano (1984) -- rather than 
reduction of DPMO: in fact coupled with human emotions, sentiments and expectations, it is near impossible to define flawlessly a "defect".

\section{ANALYTICAL ISSUES}

When educational institutes' wants to apply Six Sigma in their organizations, the greatest difficulty or barrier comes from the individuals having higher qualification and experiences with strong desire to sit on higher positions with no knowledge of the processes and their impacts. They fail to answer what is required to be done? How it is to be done? And what will be the output exactly? They try every body part other than the 'soul'. Energy is wasted in undoing what they have previously done in conventional manner.

The original Six Sigma methodology was motivated by arguments based on a normal distribution. All the concepts of 3.4 dpmo as a bench mark, z scores, short-term and long-term performances and so on, are derived and extended based on normal distributions.

While the behaviour of many natural physical quantities can be approximated by the normal distribution, the same cannot be said of common educational systems; for example the Poisson distribution is more likely to be appropriate to describe lapses in a specific type of service. With the collapse of the normal distribution background, the idea of "sigma level" as a proxy for "quality level", with the attendant arguments about improvements, comparisons and so on, is no longer valid. Thus a Six Sigma project cannot be based on concepts of "sigma level" without checking the behaviour of background data. Even if the normal distribution is a reasonable approximation, there are still arguments against the non-linear nature of "improvement"; for example the dpmo reduction for a change from five sigma level to six sigma level is very different from a change from two sigma level to three sigma level. Other controversies, such as the rationale for 1.5 sigma shift in the long term, also carry over from the study of manufacturing systems to that of educational and other service systems; the justifications are, if anything, even more uncertain or unconvincing in the latter. What is even more challenging, from a statistical modelling point of view, is that many educational systems tend to be time-variant owing to changing expectations, lifestyle, culture, demography, political decisions, and so on. Assumptions about noise behaviour, often taken for granted in the modelling of manufacturing processes, cannot be made lightly: For example, data independence is an important yet often ignored requirement in system modelling - as a result of the shallow Statistics training or knowledge of some practitioners. Merely collecting data is not quality.

\section{INSTITUTIONAL ISSUES}

A common desire of management is to attain the highest quality and achievements. They want to know about Six Sigma as they have heard it from so many sources and from media publications also. Some were promised by so called educational consultants that each project would attract flock of students and lacks of rupees. The usefulness or otherwise of such "motivation" is obvious if it is realized that not every organization operates in the same scale, same structure, same product (students) or same input (fresher). The 'environment' is 'different'.

All these exciting claims are often repeated in brochures and manuals selling Six Sigma courses which by the way are often expensive, and as a rule training or consulting fees are expected way before any real savings are realized by the clients. All these point to the need for a proper understanding of the principles and rationale behind Six Sigma before its adoption. Six Sigma is not a fad, and educational institutes should not go for it simply because the competition has it, some learned people talk about it, and they themselves feel that this is perhaps good public reputation. Institute needs to create a Six Sigma team as roadmap shown in figure 2, with rights and responsibilities given to it. The Six Sigma team will then be responsible for the way the project carried out in the institution. Institute has to select, train and motivate people in the institute for the success of the Six Sigma project. Institutes following norms of Governing body completely may find it achievable if approached properly for it.

Another possibility is to keep unrealistic expectations after hearing the propaganda from incompetent or irresponsible consultants, trainers and faculty members: disillusionment about Six Sigma after payment of hefty amount and deploying expensive manpower in vain would double the pain. To claim that Six Sigma can only lead to business success for any organization is just being irresponsible. 


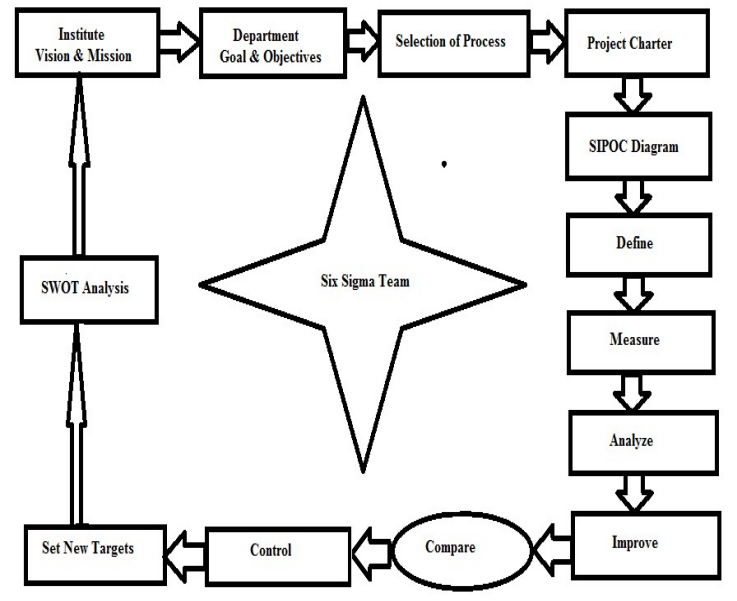

Fig. 2 Six Sigma Roadmap (local) in an Institute

\section{PERSONAL ISSUES}

Educational organizations requires individuals those can give output. Merely having eligibility does not mean the individual is suitable for the Six Sigma project. Then who can decide the right person? Overly optimistic thinking about individuals could lead to disillusion in ways as explained above, but the tendency today seems to suggest that it is not organizations, but rather individuals, that are keen about Six Sigma. Witness the advertisements for training courses for "Belts" of all sorts of colours - of course Black Belts in particular. Almost all such advertisements promise certification: certification of the individual as, for example, Black Belt, rather than an organization. This is in fact a deviation from the original motivation: to improve organizational performance and increase customer satisfaction. It is a fact that nowadays many people sign up for Six Sigma training not necessarily motivated by the operation of the company, but by the certificate that they themselves could possess at the end to improve their CV. Most training and certification programs also require demonstration of competence via a presentation on projects, which not infrequently then lead to some sort of "reverse engineering" - armed with final solutions and results, the "problem solving" or "improvement" process is developed backwards so that the resulting material would fit the expectation of the certification examiners, in a format that inevitably ends with "all is well". This is not to suggest a termination of the existing Six Sigma training and certification system. What is needed is an ability to avoid not seeing the forest for the trees, and a serious attitude toward Six Sigma projects. There is no rule that says all such projects must end in "all is well". It is "statistical thinking" that is called for in the execution of projects, and the thoroughness of its application determines the merit of the work. If this point is not appreciated, more individuals will engineer projects "suitable" for certification purposes, but the resulting Black Belts or Green Belts cannot be expected to be able to handle uncertainties of educational systems intelligently and bring credit to Six Sigma.

\section{CONCLUDING REMARKS}

Engineering educational sector is nowadays a lucrative business as it is playing important role in the economy of a country. At the same time this sector is constantly searching for better tools for improvements. Six Sigma is one such tool which offers various gains not certainly possible by others. In this hope these organisations trying for Six Sigma and at the same time it is presenting considerable challenges to those who apply it. In this paper, a counter point is shown between education, service and manufacturing, followed by discussions concerning the application of Six Sigma at the analytical, institutional and personal levels. There are varying degrees of "goodness of fit" of the descriptions when it comes to individual cases, but universal applicability is by no means implied. As the Six Sigma methodology evolves and as more training and certification programs emerge in the commercial world, it is important that a rational perspective be maintained before investments are made in Six Sigma by an organization for its deployment, or by a person for whatever manner of "certification", as unrealistic expectations could only lead to disillusionment. It is worthwhile noting that Six Sigma has been largely propagated outside academia and embraced by industry, which gives it a practical bent but would also mean that occasionally insufficient attention is paid to the related theoretical underpinning. The enthusiasm that is seen nowadays for personal certification is necessary but by no means sufficient to spread the effective practice of Six Sigma especially in educational systems. Indeed it must be said that it is only an organization with a critical mass of individuals with statistical thinking, not some certified individuals more concerned with their qualifications than customer benefits, could bring the true power to the educational institute.

\section{REFERENCES}

1) Arun Vijay S. (2013). "Appraisal of Student Rating as a Measure to Manage the Quality of Higher Education in India: An Institutional Study Using Six Sigma Model Approach," International 
Journal for Quality Research 7(4), ISSN 18006450, pp. 493-508.

2) Dragan Pavlović, Milena Todorović, Srđan Mladenović and Peđa Milosavljević (2014). "The Role of Quality Methods in Improving Education Process: Case Study," Serbian Journal of Management 9 (2) (2014), pp. 219-230.

3) Arun Vijay Subbarayalu, Ahmed Al Kuwaiti (2017). "Development of a Six Sigma Rating Scale for Measuring the Quality of Work Life of Teaching Staff Working in Saudi Universities," International Journal for Quality Research 11(2), ISSN 1800-6450, pp. 397-418.

4) Mukondeleli .G. Kanakana, Jan H.C. Pretorius and Bernard J. van Wyk (2012). "Applying Lean Six Sigma in Engineering Education at Tshwane University of Technology," Proceedings of the 2012 International Conference on Industrial Engineering and Operations Management Istanbul, Turkey, July 3 - 6, 2012, pp, 211-220.

5) Isam Elbadawi, Mohamed Aichouni and Noor Aite Messaoudene (2016). "Developing an Innovative and Creative Hands-on Lean Six Sigma Manufacturing Experiments for Engineering Education," Engineering, Technology \& Applied Science Research Vol. 6, No. 6, 2016, pp. 1297-1302.

6) Sylvie Nadeau (2017). "Lean, Six Sigma and Lean Six Sigma in Higher Education: A Review of Experiences around the World," American Journal of Industrial and Business Management, 2017, 7, ISSN Online: 2164-5175, ISSN Print: 2164-5167, pp. 591-603.

7) Abhijith.R, Akhil.BS, Sivaprakash.SC and Anshadh.A (2016). "A Study of Current Engineering Education System Under Kerala Technological University Using Six Sigma Method," International Journal On Engineering Technology and Sciences - IJETSTM ISSN (P): 2349-3968, ISSN (O): 2349-3976 Volume III, Issue III, March- 2016, pp. 52-56.

8) L Ramanan, Dr M Kumar and Dr Kpv Ramanakumar (2014). "SIX SIGMA - DMAIC Framework for Enhancing Quality in Engineering Educational Institutions," International Journal of Business and Management Invention, ISSN (Online): 2319 - 8028, ISSN (Print): 2319 801X, Volume 3 Issue 1, January 2014, pp. 36-40.

9) Majid Shoeibi \& Elmira Zahmatdoost (2015). "The Role of Six Sigma in Improving the Quality of Higher Education Institutions," The SIJ Transactions on Industrial, Financial \& Business
Management (IFBM), Vol. 3, No. 6, ISSN: 2321242X, June 2015, pp. 93-98.

10) Naveen Kumar and Dr. R.M.Belokar (2015). "Six Sigma in Education System: A Review," International Journal for Scientific Research \& Development, Vol. 3, Issue 03, 2015, ISSN (online): 2321-0613, pp. 3504-3507.

11) Marcos Buestan, Cinthia Perez and Edwin Desintonio (2016). "A proposed framework for implementing Lean Six Sigma methodology in Ecuadorian Children Hospital," 14th LACCEI International Multi-Conference for Engineering, Education, and Technology: "Engineering Innovations for Global Sustainability", 20-22 July 2016, San José, Costa Rica, pp. 1-7.

12) Sarath Sankar.R.U, Anshadh.A, Akhil.B.S and Abhijith.R (2016). "Stress Analysis of Engineering Graduates Using Six Sigma Methodology," International Journal of Research in Mechanical Engineering, Volume 4, Issue 3, May-June, 2016, ISSN Online: 2347-5188, Print: 2347-8772, pp. 159-164.

13) Mira Lalovic, Richard L. Shell and Ali A. Houshmand (2002). "The Use of Six Sigma to Improve the Quality of Engineering Education," Proceedings of the 2002 American society for Engineering Education Annual Conference \& Exposition, pp. 7.1195.1-7.1195.18.

14) Mr. Sean P. Goffnett (2004). "Understanding Six Sigma: Implications for Industry and Education," Journal of Industrial Technology, Volume 20, Number 4, pp. $02-10$.

15) Issa bass and Barbara Lawton (2009). "Lean Six SigmaUsing SigmaXL and Minitab," Mc Graw Hill, ISBN: 978-0-07-162621-7.

16) Tannu Vats and Sujata (2015). "Lean six sigma model to improve student performance," International Journal of Computer Science and Technology, IJCST Vol. 6, Issue 2, April - June 2015, ISSN : 0976-8491 (Online).

17) Chakrabarty, A., and Tan, K. C (2006). “Applying Six-Sigma in the Service Industry: A Review and Case Study in Call center services," 2006 IEEE International Conference on Management of Innovation and Technology

18) Deshmukh, S.G., N. Seth and P. Vrat (2005). "Service Quality Models: A Review," International Journal of Quality \& Reliability Management, Vol.22, No.9, pp. 913-949, 2005.

19) David Fogarty (2015). "Lean six sigma and data analytics: Integrating complementary activities," 
Global Journal of Advanced Research, 2015, Vol2, Issue-2, ISSN: 2394-5788, pp. 472 -480.

20) Prof. Thong-Ngee Goh (2012). "Some practical issues in the application of lean six sigma to service systems." Nang Yan Business Journal 1.1, 2012, pp. 21-26. 